\title{
Triggering of the endorphin analgesic reaction by a cue previously associated with shock: Reversal by naloxone
}

\author{
MICHAEL S. FANSELOW and ROBERT C. BOLLES \\ University of Washington, Seattle, Washington 98195
}

\begin{abstract}
Rats first received either forward tone-shock or backward shock-tone pairings. Then all animals were tested for the amount of freezing elicited by a single shock, which was preceded by the tone. Less freezing was observed in those animals for which the tone had been established as a predictive cue for shock. This reduction in apparent painfulness of shock, caused by preceding it with a predictive cue, was not found in animals pretreated with naloxone. The results are interpreted in terms of an endogenous analgesic system that can be triggered either by painful stimuli or by cues predicting painful stimulation.
\end{abstract}

There is much evidence pointing to the existence of a system in the mammalian brain that is biochemically and functionally related to narcotic analgesics, which is capable of inhibiting pain (Sherman \& Liebeskind, in press). A number of painful events have been shown to trigger this endogenous analgesic system in rats, among them cold water stress (Bodnar, Kelly, \& Glusman, 1978), intraperitoneal injections of acetic acid (Kokka \& Fairhurst, 1977), thermal stimulation (Jacob, Tremblay, \& Colombel, 1974; Walker, Bernston, Sandman, Coy, Schally, \& Kastin), and either severe (Madden, Akil, Patrick, \& Barchas, 1977) or moderate (Fanselow \& Bolles, in press) electric shock. The present experiment was designed to test the possibility that a stimulus that is not itself painful but that predicts a painful event is also capable of triggering the endogenous analgesic system. Chance, White, Krynock, and Rosecrans (1978) reported that exposure to a fear conditioning situation increased endogenous opiate activity in the brain as well as producing analgesia on the tail-flick test. However, their lack of conditioning controls leaves open the possibility that these effects were due simply to the unconditioned effects of the shock US and were not a conditioned triggering of the endogenous analgesic system by the CS. Other evidence for triggering of the endogenous analgesic system by a signal predicting shock was reported by Fanselow (1979), who found that naloxone attenuates the rat's preference for signaled shock. This result suggests that the rat prefers signaled shock because the signal causes conditioned release of endogenous opiates that reduce the aversiveness of the shock on the signaled side.

Supported by Grant NBS 76-19912 from the National Science Foundation. We would like to thank R. A. Sigmundi for help in running the animals, and Endo Laboratories for supplying naloxone. Reprint requests should be addressed to the first author, Department of Psychology, University of Washington, Seattle, Washington 98195.
If fear conditioning bestows the CS+ with the ability to trigger the endogenous analgesic system, then the CS+ should reduce the aversiveness of a shock that follows it. As less aversive shocks produce less freezing behavior (Fanselow \& Bolles, in press), the reduction in aversiveness should result in less postshock freezing compared to controls for whom shock was not predicted. If the reduction in aversiveness is mediated by endogenous opiates, then the reduction in freezing caused by the CS+ should be reversed by the opiate antagonist, naloxone. The present experiment tested this hypothesis.

\section{METHOD}

\section{Subjects and Apparatus}

Thirty-six adult female Long-Evans rats served as subjects. The rats were housed individually and maintained on ad-lib food and water. The experiment was conducted during the light portion of a $12: 12$ day/night cycle.

Fear conditioning occurred in one of four $38 \times 20 \times 18 \mathrm{~cm}$ wooden conditioning boxes, placed inside of sound-attenuating cabinets. There was no illumination in the conditioning boxes. The CS was a $5,000-\mathrm{Hz}$ tone $\left(80 \mathrm{~dB}\right.$ re $20 \mu \mathrm{N} / \mathrm{m}^{2}$, background $=$ $64 \mathrm{~dB})$. The US was a shock of approximately $.71 \mathrm{~mA}$, as measured by a $150-\mathrm{kohm}$ resistor substituted for the rat, delivered through the grid floor. The conditioning box was cleaned with a $2 \%$ vinegar and water solution between rats.

The observation chamber measured $26 \times 23 \times 24 \mathrm{~cm}$. The ceiling and front viewing wall were made of Plexiglas, the remaining walls of stainless steel. A $1.0-\mathrm{mA}$ scrambled shock could be delivered through the grid floor. Illumination was provided by a 7.5 -W white light bulb suspended $5 \mathrm{~cm}$ above the ceiling. All auditory stimuli matched those in the conditioning boxes. The observation chamber was cleaned with a $1 \%$ detergent (Vestal, 1-Stroke Ves-Phene) and water solution between rats. The observation chamber was placed in a soundattenuating chest.

\section{Procedure}

The rats were each handled for $2 \mathrm{~min} /$ day for 4 days before the experiment began. On Day 1 of the experiment, the rats were placed in the conditioning boxes. Half of the rats received 
forward conditioning; the other half served as controls, receiving backward conditioning. In forward conditioning, a 30-sec CS terminated with the onset of the $.75-\mathrm{sec}$ US; in backward conditioning, US offset was simultaneous with the onset of the 30-sec CS. Each rat received 15 of the appropriate conditioning trials on a $280-\mathrm{sec}$ variable-time schedule.

On Day 2 some of the rats were given an IP injection of naloxone hydrochloride in an isotonic saline vehicle. One-third of the rats received $4 \mathrm{mg} / \mathrm{kg}$ naloxone, one-third received $1 \mathrm{mg} / \mathrm{kg}$ naloxone, and one-third served as drug controls, receiving only saline. Half of each drug group had previously received forward conditioning, and half backward conditioning.

Immediately after the injection, the rats were placed in the observation chamber. After $2 \mathrm{~min}$, the CS was presented for $30 \mathrm{sec}$; .75 -sec shock occurred immediately at CS offset. The animals remained in the chamber for an additional $8 \mathrm{~min}$. An observer, blind to the animals' drug and conditioning histories, observed the animals while they were in the observation chamber. Every $4 \mathrm{sec}$ the animal's behavior was classified as either freezing or activity. Freezing was defined as the absence of observable skeletal and vibrissae movements, except for those necessitated by respiration. All other behavior was classified as activity.

\section{RESULTS}

During the first 2 min in the observation chamber, all animals were active; freezing occurred on only $2 \%$ of the behavior samples during this period. A 2 by 3 factorial analysis of variance indicated that there were no differences between groups (all Fs $<1$ ) during this period.

A 2 by 3 factorial analysis of variance on the mean - percent of the behavior samples scored as freezing during the 30-sec CS yielded a significant difference between animals receiving forward and backward conditioning $[F(1,30)=33.57, p<.005]$, indicating that the training procedure had made the forward-conditioned auditory stimulus a Pavlovian CS+. Neither the main effect for drug nor the interaction of drug and conditioning factors was reliable $(\mathrm{Fs}<1)$, indicating that naloxone did not affect conditioned fear. These data are presented in Figure 1.

The data for the percentage of time spent freezing during the 8-min period following shock are presented in Figure 2. There was a reliable interaction between the conditioning and drug factors $[\mathrm{F}(2,30)=4.04, \mathrm{p}<.05]$. The animals that had forward conditioning and no drug pretreatment (saline controls) froze less following shock than any of the other groups $(p<.05)$. No other differences between groups were significant.

\section{DISCUSSION}

When a shock was preceded by a signal predicting shock, rats froze less than control animals for which shock was preceded by a nonpredictive stimulus. This effect was reversed in the two groups receiving naloxone. These results suggest that a Pavlovian CS+ for shock can trigger the rat's endogenous analgesic system. The absence of such a pattern among the backward control animals indicates that these effects are not attributable solely to CS or US preexposure; it is the predictive

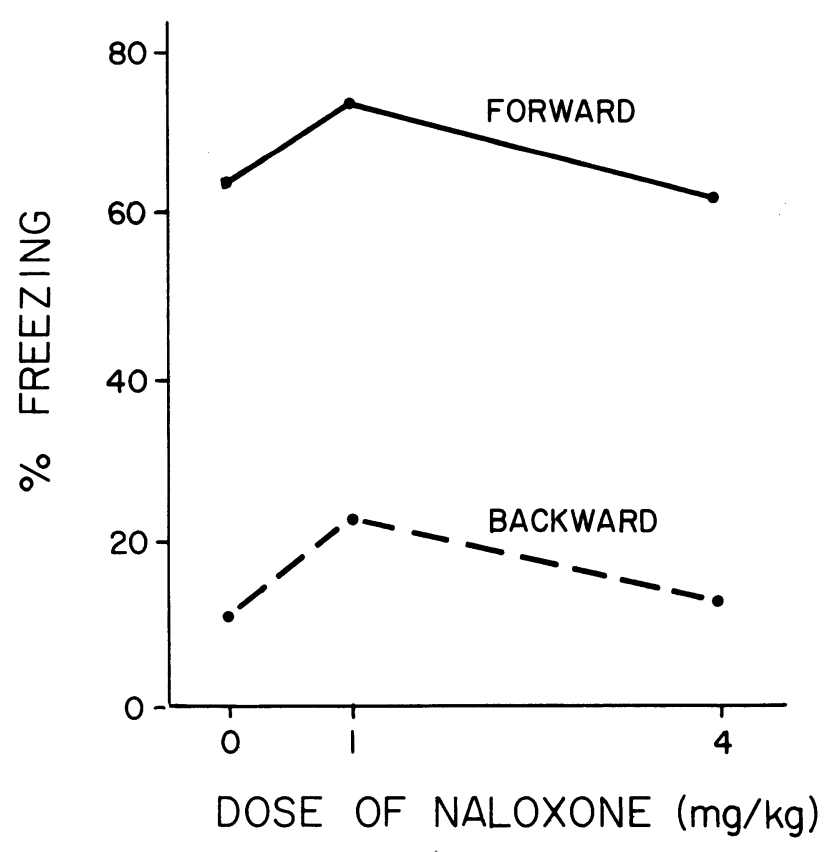

Figure 1. Mean percentage of freezing observed in the different groups during the $30-\mathrm{sec}$ CS.

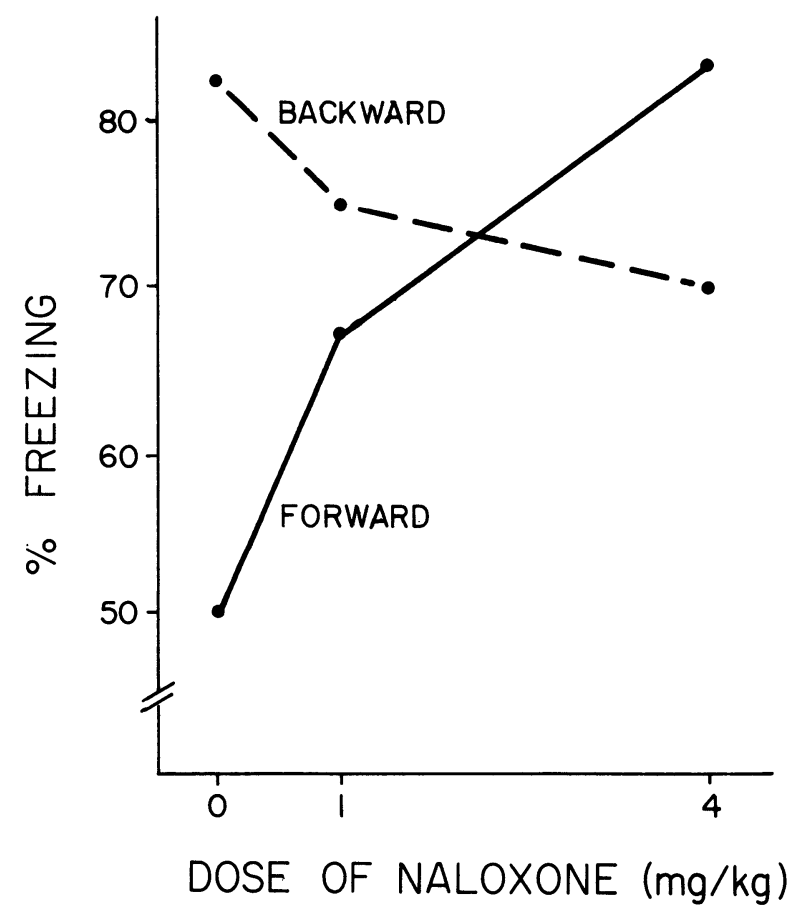

Figure 2. Mean percentage of freezing during the $8 \mathrm{~min}$ immediately following the CS.

character of the CS+ that reduces the freezing elicited by the US. If we can assume that the amount of freezing elicited by a painful shock is dependent upon how painful the shock is, and there is now good evidence to support such an assumption (Fanselow \& Bolles, in press), then we can conclude that the endogenous analgesic system can be triggered by a CS+ that predicts painful stimulation. 
We have spoken here as though postshock freezing were in some way elicited by shock. Perhaps, a more accurate view of freezing is to regard it as a response to contextual cues that have been associated with shock (Blanchard \& Blanchard, 1969; Bolles \& Collier, 1976). Then, as the painfulness of shock is increased, either by increasing its physical intensity or by not signaling it with a CS+ that would trigger the endogenous analgesic system, or by antagonizing that system with naloxone, more fear will be conditioned to contextual cues, and hence more freezing would occur. Thus our inferences about the analgesic system do not depend upon what particular interpretation we give to the immediate cause of freezing behavior.

The action of naloxone appears to be quite specific; it only increases freezing following a single shock if that shock is preceded by a CS + . Naloxone does not increase postshock freezing when a shock of the same duration and intensity is given alone (Fanselow \& Bolles, in press) or if it is preceded by a nonpredictive stimulus (present experiment). Naloxone did not appear to have a direct effect upon conditioned fear, as measured by freezing during the tone. Similarly, Fanselow and Bolles (in press) have found that naloxone enhances postshock freezing if given before but not after a series of shocks. This pattern of results indicates that the effect of naloxone on freezing is mediated by a modification in the pain of the shock and not upon fear. Furthermore, this modification in the painful stimulus is noted only if some event (e.g., a CS+ or another shock) occurs before the shock. This suggests that the first event normally triggers the endogenous analgesic system and naloxone makes the shock more painful by antagonizing this analgesia.

The data suggest a biological role of the endogenous opiate system in the modification of pain in certain situations. When some situation is perceived as dangerous, either because of the presence of painful stimulation, or cues that predict painful stimulation, or because of innate recognition of a predator, the the rat's behavior is dominated by species-specific defense reactions (Bolles, 1970). If these same events trigger the endogenous analgesic system, then the pain of any injurious stimulation will be less likely to interfere with the rat's defensive behavior. If successful escape or defense removes the threat, then the analgesia would dissipate and at that point the pain of any injuries received would be felt. This pain would result in suppression of the animal's normal activities, as well as causing it to engage in recuperative behaviors.

\section{REFERENCES}

Blanchard, R. J., \& Blanchard, D. C. Crouching as an index of fear. Journal of Comparative and Physiological Psychology, 1969, 69, 370-375.

Bodnar, R. J., Kelly, D., \& Glusman, M. Stress-induced analgesia: Time course of pain reflex alternations following cold water swims. Bulletin of the Psychonomic Society, 1978, 11, 333-336.

Bolles, R. C. Species-specific defense reactions and avoidance learning. Psychological Review, 1970, 77, 32-48.

Bolles, R. C., \& Collier, A. C. The effect of predictive cues on freezing in rats. Animal Learning \& Behavior, 1976, 4, 6-8.

Chance, W. T., White, A. C., Krynock, G. M., \& Rosecrans, J. A. Conditioned fear-induced antinociception and decreased binding of $\left[{ }^{3} \mathrm{H}\right] \mathrm{N}$-Leu-enkephalin to rat brain. Brain Research, 1978, 141, 371-374.

FANSELOW, M. S. Naloxone attenuates rat's preference for signaled shock. Physiological Psychology, 1979, 7, 70-74.

Fanselow, M. S., \& Bolles, R. C. Naloxone and shock-elicited freezing in the rat. Journal of Comparative and Physiological Psychology, in press.

Jacob, J. J., Tremblay, E. L., \& Colombel, M. C. Facilitation de reactions nocioceptives par la naloxone chez la souris et chez le rat. Psychopharmacologia, 1974, 37, 217-223.

KokKA, N., \& FAIrhurst, A. S. Naloxone enhancement of acetic acid-induced writhing in rats. Life Sciences, 1977, 21, 975-980.

Madden, J., Akil, H., Patrick, R. L., \& Barchas, J. D. Stress-induced parallel changes in central opioid levels and pain responsiveness in the rat. Nature, 1977, 265, 358-360.

Sherman, J. E., \& Liebeskind, J. C. An endorphinergic, centrifugal substrate of pain modulation: Recent findings, current concepts and complexities. Proceedings, Association for Research in Nervous and Mental Disease. New York: Raven Press, in press.

Walker, J. M., Bernston, G. G., Sandman, C. A., Coy, D. H., Schally, A. V., \& Kastin, A. J. An analog of enkephalin having prolonged opiate-like effects in vivo. Science, 1977, 196, 85-87.

(Received for publication April 19, 1979.) 